\title{
ALTURA DE CORTE E ADIÇÃO DE INOCULANTE ENZIMO- BACTERIANO NA COMPOSIÇÃ̃O QUÍMICO-BROMATOLÓGICA E DIGESTIBILIDADE DE SILAGENS DE MILHO AVALIADA EM OVINOS
}

\author{
CUTTING HEIGHT AND ADDITION OF ENZYME-BACTERIAL \\ INOCULANTS ON CORN SILAGE CHEMICAL COMPOSITION AND \\ DIGESTIBILITY IN SHEEP
}

\author{
Fabiany Izabel Marquardt ${ }^{1}$ \\ Clóves Cabreira Jobim ${ }^{1 *}$ \\ Antonio Vinicius lank Bueno ${ }^{1}$ \\ Matheus Gonçalves Ribeiro ${ }^{1}$ \\ 1Universidade Estadual de Maringá, Maringá, PR, Brasil \\ *Autor para correspondência - ccjobim@uem.br
}

\section{Resumo}

Objetivou-se com este ensaio observar a influência da altura de corte da planta de milho, associada ou não a um inoculante enzimo-bacteriano, sobre a composição químico-bromatológica e digestibilidade das silagens avaliadas em ovinos. Os tratamentos foram silagens de milho colhidas a 20 e 40 centímetros acima do nível do solo, com ou sem inoculante. Utilizou-se como inoculante o aditivo Maize-All ${ }^{\circledR}$. As variáveis analisadas na silagem foram $\mathrm{pH}$, matéria seca, matéria orgânica, proteína bruta, extrato etéreo, fibra em detergente neutro, fibra em detergente ácido, hemicelulose, celulose, lignina e carboidratos não fibrosos. No ensaio de digestibilidade, avaliou-se a digestibilidade aparente da MS, MO, PB, EE, FDN, FDA, Hem e CNF. Observou-se com a elevação da altura de corte redução na concentração de lignina, o milho colhido a $20 \mathrm{~cm}$ apresentou uma concentração superior ao colhido a $40 \mathrm{~cm}$, verificando-se concentrações de $84,0 \mathrm{~g}$. $\mathrm{kg}^{-1} \mathrm{MS}$ e $69,3 \mathrm{~g}$. $\mathrm{kg}^{-1} \mathrm{MS}$, respectivamente, não havendo efeito da inoculação. Não foi observado efeito significativo dos tratamentos sobre as digestibilidades. A elevação da altura de corte apresentou alteração apenas nas concentrações de lignina. No entanto, essa redução de lignina não influenciou nas digestibilidades e consequentemente não alterou as concentrações de NDT.

Palavras-chave: aditivo; corte alto; enzimas.

\begin{abstract}
The objective of this experiment was to observe the influence of the height of corn plant cutting, associated or not with an enzyme-bacterial inoculant or not, on the chemical composition and digestibility of the silage in sheep. The cut heights were 20 and 40 centimeters above the soil. The additive inoculant was Maize-All ${ }^{\circledR}$. We analyzed on silage: $\mathrm{pH}$; dry matter; organic matter; crude protein; ether extract; neutral detergent fiber; acid detergent fiber; hemicellulose; cellulose; lignin; and non-fibrous carbohydrates. At the digestibility trial we evaluated apparent digestibility of DM, OM, CP, EE, NDF, ADF, Hem, Cel and NCF. We observed that a high cut reduced lignin value. The
\end{abstract}


corn silage harvested at $20 \mathrm{~cm}$ had $84.0 \mathrm{~g} . \mathrm{kg}^{-1} \mathrm{DM}$ of lignin, higher value than the corn silage harvested at $40 \mathrm{~cm}\left(69.3 \mathrm{~g} . \mathrm{kg}^{-1} \mathrm{MS}\right)$, and there was no effect of inoculation. There were no differences among treatments at the digestibility trial. The cutting height reduced just lignin concentration. However, this lignin reduction did not affect digestibility and hence it did not affect the TDN concentration.

Keywords: additive; enzymes; high cut

Recebido em: 24 agosto de 2016

Aceito em: 16 janeiro 2017

\section{Introdução}

Uma alternativa para melhorar o valor nutritivo da silagem de milho é elevar a altura de corte das plantas, concentrando grãos e reduzindo a participação de colmo e folhas senescentes, componentes que apresentam maiores teores de lignina e fibras de baixa digestibilidade ${ }^{(1)}$. No entanto, com a elevação da altura de corte ocorre redução na massa de forragem ensilável ${ }^{(2)}$. Assim, a tomada de decisão deve considerar a relação custo:benefício (quantidade $v s$. qualidade) do volumoso produzido. No Brasil, visando acelerar o processo fermentativo e maior eficiência na preservação das silagens, o uso de inoculantes microbianos tem sido adotado em muitas propriedades rurais ${ }^{(3,4)}$. Dentre as bactérias mais utilizadas como inoculantes para silagens, destacam-se as heteroláticas Lactobacillus plantarum, L. acidophilus, Pediococcus acidilactici, P. pentacaceus e Enterococcus faecium, produtoras de ácido lático a partir da fermentação de açúcares simples, resultando em perdas mínimas de energia e matéria seca ${ }^{(5)}$.

Associado aos inoculantes, tem se observado também o uso de enzimas na produção de silagens, destacando-se as celulases, hemicelulases e amilases ${ }^{(6-9)}$. Estas enzimas auxiliam na degradação de constituintes da parede celular e do amido, liberando açúcares solúveis que poderão ser utilizados como substrato pelas bactérias, ou mesmo pelos animais alimentados com as silagens.

Perante o exposto, objetivou-se com o presente estudo avaliar diferentes alturas de corte do milho, somadas ao uso de inoculantes enzimo-bacteriano, no valor nutricional das silagens oferecidas a ovinos.

\section{Material e Métodos}

O experimento foi conduzido na Fazenda Experimental de Iguatemi (FEI) e as análises químicas realizadas no Laboratório de Análises de Alimentos e Nutrição Animal, ambos pertencentes ao Departamento de Zootecnia da Universidade Estadual de Maringá.

Foi utilizado o milho, híbrido Dekalb 789, estabelecido em uma área de 7 ha com população de 60 mil plantas.ha ${ }^{-1}$, com espaçamento de $0,9 \mathrm{~m}$ entre linhas. A colheita da forragem foi realizada quando o grão do milho apresentava $1 \frac{1}{2}$ da linha do leite, com uso de uma ensiladeira JF90Z10 regulada para 
corte do material em tamanho médio de partícula de $10 \mathrm{~mm}$. As silagens foram armazenadas em quatro silos tipo trincheira revestidos, com dimensões de $3,40 \mathrm{~m}$ de base por $1,10 \mathrm{~m}$ de altura $\left(3,74 \mathrm{~m}^{2}\right)$ e $13 \mathrm{~m}$ de comprimento, num volume total de $48,62 \mathrm{~m}^{3}$, e em cada silo foram armazenadas cerca de $26 \mathrm{Mg}$ de forragem.

Os tratamentos foram: planta de milho colhida a 20 ou $40 \mathrm{~cm}$ do solo, com ou sem adição de inoculante. O inoculante utilizado foi o Maize - All ${ }^{\circledR}$, produto composto de Lactobacillus plantarum, Enterococcus faecium ( 1 x $\left.10^{10} \mathrm{ufc}^{-1} \mathrm{~g}^{-1}\right)$ e Pediococcus acidilactici $\left(1 \times 10^{9} \mathrm{ufc}_{\mathrm{f}} \mathrm{g}^{-1}\right)$, assim como enzimas amilolíticas, celulolíticas e dextrose. $\mathrm{O}$ inoculante foi aplicado com o uso de pulverizador costal conforme as recomendações do fabricante, com uma dose de $1 \times 10^{5} \mathrm{UFC}_{\mathrm{g}} \mathrm{g}^{-1}$ de forragem. A mesma quantidade de água foi adicionada em todos os tratamentos. Após um período de armazenagem de 150 dias, os silos foram abertos para as avaliações propostas no presente estudo.

As amostras de silagem para avaliação da composição químico-bromatológica foram coletadas aleatoriamente no silo durante os períodos de coleta no ensaio de digestibilidade in vivo em ovinos, totalizando quatro amostras por tratamento. Foram utilizados quatro ovinos machos com aproximadamente $30 \mathrm{~kg}$ de peso vivo, distribuídos em um quadrado latino 4 x 4 . Os animais foram mantidos em gaiolas de metabolismo com o piso ripado, comedouro e bebedouro individuais, onde receberam alimento duas vezes ao dia, pela manhã e pela tarde, e água à vontade. As dietas eram compostas de $70 \%$ de volumoso e $30 \%$ de um concentrado comercial (89,0\% de MS; 91,3\% de MO; $20,0 \%$ PB; $32,0 \%$ de FDN e 75,0\% de NDT), sempre visando a uma sobra de $10 \%$ do total fornecido.

Após um período inicial de 14 dias de adaptação às instalações, à silagem de milho e à relação volumoso:concentrado, foram conduzidos quatro períodos experimentais de 15 dias cada, com 11 dias de adaptação e quatro dias de coletas de fezes. As fezes foram coletadas de manhã pelo método de coleta total com uso de bolsa de napa, própria para esse tipo de coleta. Em seguida o material foi homogeneizado e retirada uma alíquota diária de $10 \%$ do total, para posterior formação de uma amostra composta por animal e por período experimental. Essas amostras foram armazenadas em sacos plásticos e congeladas em freezer a $-20{ }^{\circ} \mathrm{C}$ para análises posteriores. Foram feitas também amostragens da ração total e das sobras nos dias das coletas de fezes.

Após os períodos de coleta, as amostras foram secas em estufa de ventilação forçada a $55^{\circ} \mathrm{C}$ por 72 horas e posteriormente moídas a $1 \mathrm{~mm}$ em moinho tipo faca. As análises de matéria seca (MS), proteína bruta $(\mathrm{PB})$, extrato etéreo (EE) e matéria orgânica (MO) foram realizadas de acordo com metodologia proposta pela $\mathrm{AOAC}^{(10)}$ e as determinações de $\mathrm{pH}$ conforme Cherney \& Cherney ${ }^{(11)}$.

Para determinação de fibra em detergente neutro (FDN), fibra em detergente ácido (FDA), lignina em detergente ácido (LDA) e celulose (Cel) foi utilizada a metodologia proposta por Van Soest et al. ${ }^{(12)}$. A hemicelulose (Hemi) foi obtida pela diferença entre FDN e FDA. Os valores de carboidratos não fibrosos (CNF) foram calculados conforme equação proposta pelo $\mathrm{NRC}^{(13)}$, em que $\mathrm{CNF}=100-(\mathrm{FDN}+\mathrm{PB}+\mathrm{EE}+\mathrm{MM})$.

O coeficiente de digestibilidade aparente dos nutrientes foi obtido pela diferença entre a sua ingestão e excreção, pela seguinte equação:

$$
D \text { nutriente }=\{(\text { ingerido }- \text { excretado }) / \text { ingerido }\} \times 100 .
$$

Para determinar o teor de nutrientes digestíveis totais (NDT), utilizaram-se os valores PB $_{\text {dig }}, F_{\text {FDN }}$, $\mathrm{EE}_{\text {dig }}$, e $\mathrm{CNF}_{\text {dig }}$, empregando-se a fórmula: $\mathrm{NDT}(\% \mathrm{MS})=\mathrm{PB}_{\mathrm{dig}}+\mathrm{EE}_{\mathrm{dig}}$ x 2,25 $+\mathrm{FDN}_{\mathrm{dig}}+\mathrm{CNF}_{\text {dig. }}$. 
O delineamento utilizado para avaliação da composição químico-bromatológica das silagens foi em blocos casualizado, considerando-se como bloco o período de coleta das silagens, em esquema fatorial 2 x 2, sendo avaliado pelo presente modelo:

$$
\mathrm{Y}_{\mathrm{ijk}}=\mu+\mathrm{A}_{\mathrm{i}}+\mathrm{I}_{\mathrm{j}}+\mathrm{P}_{\mathrm{k}}+\mathrm{AI}_{\mathrm{ij}},+\mathrm{e}_{\mathrm{ijk}}
$$

Em que: $Y_{i j}=$ Observação da altura i no período $\mathrm{k}$ e dentro do tratamento $\mathrm{j} ; \mu=$ média dos tratamentos; $A_{i}=$ efeito da altura de corte i (20 e 40); $I_{j}=$ efeito da inoculação $j$ (Inoculado ou não); $P_{k}=$ efeito do período $\mathrm{k}$, variando de 1 a 4; $\mathrm{AI}_{\mathrm{ij}}=$ interação entre os fatores $\mathrm{A}_{\mathrm{i}}$ e $\mathrm{I}_{\mathrm{j}}$ e $\mathrm{e}_{\mathrm{ikj}}=$ erro aleatório associado a cada observação ij.

Nas avaliações de digestibilidade foi empregado o delineamento em quadrado latino 4 x 4 com o seguinte modelo:

$$
Y_{i j k}=\mu+S_{i}+P_{j}+A_{k}+e_{i j k}
$$

Em que: $Y_{\mathrm{ijk}}=$ Observação do tratamento i no período $\mathrm{k}$ e no animal $\mathrm{j} ; \mu=$ média dos tratamentos; $\mathrm{S}_{\mathrm{i}}$ $=$ efeito da silagem $\mathrm{i}$, variando de 1 a $4 ; \mathrm{P}_{\mathrm{j}}=$ efeito do período $\mathrm{j}$, variando de 1 a $4 ; \mathrm{A}_{\mathrm{K}}=$ efeito do animal k, variando de 1 a 4; e e $e_{i j k}=$ erro aleatório associado a cada observação ijk.

Os dados foram submetidos à análise de variância com significância de 5\% com o uso do sofware estatístico $R$ versão 3.2.3, por meio do package ExpDes.pt $t^{(14)}$, comparados pelo teste $\mathrm{F}$. Quando constatada diferença pelo teste $\mathrm{F}(\mathrm{P}<0,05)$, as médias foram submetidas ao teste Tukey.

\section{Resultados e Discussão}

Os valores de $\mathrm{pH}$, matéria seca (MS), matéria orgânica (MO), proteína bruta (PB), extrato etéreo (EE), carboidratos não fibrosos (CNF), fibra em detergente neutro (FDN) e ácido (FDA), hemicelulose $(\mathrm{Hem})$, celulose $(\mathrm{Cel})$ e lignina $(\mathrm{Lig})$, obtidos no ensaio de avaliação da composição das silagens de milho do presente estudo, encontram-se na Tabela 1.

Os valores de $\mathrm{pH}$ das silagens não diferiram $(\mathrm{P}>0,05)$, com média de 3,93, o que indica que houve boa qualidade de fermentação em todos os tratamentos. Valores de $\mathrm{pH}$ abaixo de 4 indicam que o processo fermentativo foi satisfatório ${ }^{(8)}$.

Entre os valores de MS não foram observadas diferenças (P > 0,05), obtendo-se o valor médio de 319 g MS.kg-1 na MN. Assim como no presente estudo, Kung Jr. et al. ${ }^{(15)}$, avaliando diferentes alturas de corte em milho BMR (Brown midrib), também observaram o mesmo comportamento sobre as concentrações de MS, não diferindo $(\mathrm{P}>0,05)$ das demais silagens.

As concentrações de MO nas silagens apresentaram em média 958 g.kg-1 MS. Resultados apresentados por Tres et al. ${ }^{(16)}$ para forragem in natura foram semelhantes aos do presente estudo, uma vez que os autores justificaram que esta é uma variável que pode ser influenciada pelo hibrido, nível de fertilidade do solo e adubação da cultura.

As silagens, em todos os tratamentos, apresentaram valores médios de PB de 78,8 g. $\mathrm{kg}^{-1} \mathrm{MS}$. Para esta variável, não se verificou influência da altura de corte nem da inoculação (Tabela 1). Mesmo comportamento sobre os teores de PB foram obtidos por outros autores ${ }^{(9,17,18)}$. 
Tabela 1. Composição bromatológica e pH de silagens de milho (Zea maiz (L.)) colhida em diferentes alturas e inoculadas com aditivos enzimo-bacteriano

\begin{tabular}{|c|c|c|c|c|c|c|c|c|c|c|c|}
\hline & pH & MS $^{1}$ & $\mathrm{MO}^{2}$ & $\mathrm{~PB}^{2}$ & $\mathrm{EE}^{2}$ & $\mathrm{CNF}^{2}$ & FDN $^{2}$ & FDA $^{2}$ & $\mathrm{Hem}^{2}$ & $\mathrm{Cel}^{2}$ & Lig $^{2}$ \\
\hline & \multicolumn{11}{|c|}{ Altura de corte $(\mathrm{cm})$} \\
\hline 20 & 3,94 & 318 & 960 & 79,0 & 19,0 & 329 & 534 & 322 & 212 & 230 & $84,0 \mathrm{a}$ \\
\hline 40 & 3,92 & 321 & 956 & 78,5 & 22,8 & 329 & 526 & 322 & 204 & 233 & $69,3 \mathrm{~b}$ \\
\hline \multirow[t]{2}{*}{$P$ valor } & 0,79 & 0,51 & 0,24 & 0,66 & 0,10 & 0,97 & 0,49 & 0,98 & 0,54 & 0,73 & 0,02 \\
\hline & \multicolumn{11}{|c|}{ Inoculação } \\
\hline Sem & 3,97 & 314 & 958 & 79,5 & 21,9 & 321 & 535 & 327 & 208 & 233 & 73,1 \\
\hline Com & 3,89 & 325 & 958 & 78,0 & 19,8 & 337 & 524 & 316 & 208 & 229 & 80,2 \\
\hline$P$ valor & 0,44 & 0,05 & 0,81 & 0,14 & 0,34 & 0,21 & 0,32 & 0,56 & 0,97 & 0,65 & 0,18 \\
\hline Média & 3,93 & 319 & 958 & 78,8 & 20,9 & 329 & 530 & 322 & 208 & 231 & 76,6 \\
\hline $\mathrm{CV}^{3}$ & 5,07 & 3,16 & 0,71 & 2,41 & 19,58 & 6,72 & 4,17 & 11,47 & 12,64 & 6,78 & 12,77 \\
\hline $\mathrm{A} \times \mathrm{I}^{4}$ & 0,24 & 0,13 & 0,46 & 0,26 & 0,22 & 0,65 & 0,69 & 0,76 & 0,45 & 0,51 & 0,38 \\
\hline $\begin{array}{l}{ }^{1} \text { Mátéria } \\
\text { represent } \\
\text { Inoculaçãă } \\
\text { etéreo; } \\
\text { detergent }\end{array}$ & 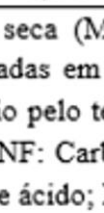 & - & 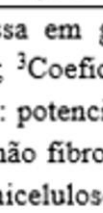 & 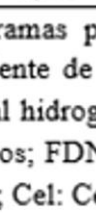 & vilog & 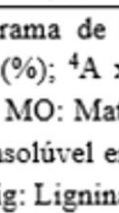 & natéria & 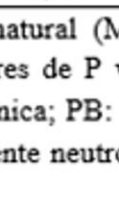 & $\mathrm{AN})(\mathrm{g} \cdot \mathrm{kg}$ & MN) & $\begin{array}{l}\text { inidades } \\
\text { Altura } \mathrm{x} \\
\text { Extrato }\end{array}$ \\
\hline
\end{tabular}

Para os teores de EE não se observou diferença ( $\mathrm{P}>0,05)$, apresentando em média valores de 20,9 g. $\mathrm{kg}^{-1}$ MS. Uma vez que a maior contribuição dos lipídeos contidos na forragem de milho provém das folhas e dos grãos ${ }^{(19)}$, pode-se afirmar que a elevação da altura de corte não interferiu significativamente na concentração dessas estruturas da planta na massa ensilada. No entanto, constatou-se que o corte do milho a $40 \mathrm{~cm}$ do solo resultou em aumento de 3,8 pontos percentuais no teor de EE, o que pode ser devido ao aumento de grãos na silagem.

As concentrações de CNF também não diferiram entre os tratamentos, com valor médio de $329 \mathrm{~g} . \mathrm{kg}^{-1}$ MS. Essa ausência de diferença se deu pela similaridade entre os valores de EE, PB, MM e FDN das diferentes silagens. As concentrações de FDN variaram entre 537 e 517 g. $\mathrm{kg}^{-1} \mathrm{MS}$, enquanto o FDA apresentou valores médios entre 330 e 313 g. $\mathrm{kg}^{-1}$ MS. O mesmo comportamento foi observado nos teores de celulose e hemicelulose, que apresentaram em média entre 231 e 208 g.kg $^{-1} \mathrm{MS}$.

Apesar dessa diferença de valores (3,72\% de diferença na FDN e 5,15\% na FDA), a ausência de diferença estatística pode ser justificada pelo fato de que em cortes mais baixos se tem uma maior contribuição de colmo na massa ensilada. No entanto, em cortes mais altos tem-se um aumento na proporção de brácteas e sabugo, componentes que podem apresentar proporções de constituintes fibrosos maiores que o colmo ${ }^{(20)}$.

Dependendo da elevação da altura de corte, as alterações nos constituintes fibrosos da silagem podem ser mínimas; no entanto, podem acarretar considerável declínio no rendimento por área ${ }^{(21-23)}$. Lauer ${ }^{(24)}$ observou redução de $15 \%$ no rendimento por área, quando a altura de corte foi elevada de $15 \mathrm{~cm}$ para $45 \mathrm{~cm}$.

Com o aumento da altura de corte observou-se efeito $(\mathrm{P}=0,02)$ nos teores de lignina (Tabela 1), em que as silagens produzidas com as plantas de milho colhidas a $40 \mathrm{~cm}$ reduziram em $17,5 \%$ o teor de 
lignina em comparação às silagens de plantas ceifadas a $20 \mathrm{~cm}$ do nível do solo. Mesmo comportamento foi observado em outros trabalhos ${ }^{(1,2,15,25)}$, uma vez que cortes mais baixos apresentam maiores contribuição de colmo na massa ensilada. Assis et al. ${ }^{(26)}$, avaliando as características de híbridos para ensilagem, observaram que os materiais que apresentaram maiores teores de lignina também apresentaram maiores proporções de colmo.

A adição de inoculante enzimo-bacteriano não interferiu no pH das silagens, nem na composição bromatológica. Em ensaio com silagens de milho colhidas em diferentes estádios de maturação aditivadas com diferentes inoculantes, Rabelo et al. ${ }^{(18)}$ também não verificaram diferença entre a silagem controle e as inoculadas com aditivo enzimo-baterianos. Os valores de $\mathrm{pH}, \mathrm{MO}$ e $\mathrm{PB}$ para o milho colhido na $1 / 2$ linha de leite não foram alterados pelo efeito do inoculante, também não observaram alteração nas concentrações de MS e lignina. Na literatura referente ao uso de inoculantes em silagens de milho, observa-se grande inconsistência de resultados. Contudo, pode se afirmar que a microflora epifítica de bactérias ácido-láticas da cultura do milho é suficiente para proporcionar fermentação desejável.

Ressalta-se que o papel principal de um inoculante microbiológico é competir com microrganismos indesejáveis, aumentando a população de BAL, acelerando o processo fermentativo e reduzindo o tempo de fermentação.

Os resultados do ensaio para determinar o coeficiente de digestibilidade aparente da matéria seca (DMS), matéria orgânica (DMO), proteína bruta (DPB), extrato etéreo (DEE), fibra em detergente neutro (DFDN), fibra em detergente ácido (DFDA), hemicelulose (DHem) e carboidratos não fibrosos (DCNF) estão apresentados na Tabela 2, bem como os valores dos nutrientes digestíveis totais (NDT) das dietas fornecidas aos ovinos.

No ensaio que determina o coeficiente de digestibilidade aparente não foram constatadas diferenças $(\mathrm{P}>0,05)$ entre os diferentes tratamentos em nenhuma das variáveis. Nos valores de NDT também não se observou diferença estatística, sendo que o valor médio encontrado de $607,1 \mathrm{~g}^{\mathrm{kg}} \mathrm{kg}^{-1} \mathrm{de} \mathrm{MS}$ ingerida é considerado baixo para dietas contendo silagem de milho. O que ocasionou os baixos valores de NDT foi a baixa digestibilidade da fração fibrosa (DFDN, DFDA). As DFDN, DFDA e as concentrações de NDT foram inferiores aos apresentados por Santos et al. ${ }^{(27)}$; no entanto, o trabalho citado ofereceu apenas silagem de milho, o que tende a aumentar o tempo de retenção, aumentando assim os valores de digestibilidade do componentes fibrosos.

Mais estudos avaliando diferentes alturas de cortes são necessários, uma vez que há na literatura uma inconsistência de dados em diversos trabalhos, variação essa possivelmente causada pela diferença entre híbridos comerciais. Outro ponto a ser observado é a viabilidade financeira de tal manejo, uma vez que se pode aumentar a eficiência alimentar individual e reduzir a eficiência produtiva por área, variável importante que não foi avaliada neste trabalho. 
Tabela 2. Coeficientes de digestibilidade aparente e concentração de nutrientes digestiveis totais de dietas contendo silagens de milho colhidas em diferentes alturas de corte e inoculadas com aditivo ezimo-bacteriano, em cordeiros

\begin{tabular}{|c|c|c|c|c|c|c|c|}
\hline \multirow{2}{*}{ Variáveis ${ }^{1}$} & \multicolumn{4}{|c|}{ Silagens $^{2}$} & \multirow{2}{*}{ Média } & \multirow{2}{*}{ P valor } & \multirow{2}{*}{$\mathrm{CV}^{*}$} \\
\hline & $20 \mathrm{~S}$ & $20 \mathrm{C}$ & $40 \mathrm{~S}$ & $40 \mathrm{C}$ & & & \\
\hline$\overline{D M S}$ & 635,5 & 608,0 & 612,6 & 621,2 & 619,3 & 0,60 & 4,78 \\
\hline DMO & 650,7 & 622,3 & 623,9 & 638,5 & 633,8 & 0,57 & 4,91 \\
\hline DPB & 713,6 & 655,7 & 689,0 & 691,5 & 687,4 & 0,12 & 4,02 \\
\hline DEE & 812,5 & 803,1 & 843,2 & 878,9 & 834,4 & 0,27 & 6,39 \\
\hline DFDN & 425,3 & 384,4 & 386,6 & 373,7 & 392,5 & 0,47 & 11,69 \\
\hline DFDA & 398,0 & 328,1 & 349,8 & 341,1 & 354,2 & 0,76 & 27,43 \\
\hline DHem & 455,9 & 445,1 & 429,6 & 413,0 & 435,9 & 0,95 & 26,16 \\
\hline DCNF & 927,0 & 919,7 & 923,4 & 943,0 & 928,3 & 0,18 & 1,46 \\
\hline NDT & 619,5 & 598,7 & 602,4 & 607,7 & 607,1 & 0,81 & 5,31 \\
\hline
\end{tabular}

'DMS: Digestibilidade aparente da matéria seca (g.kg ${ }^{-1}$ de MS ingerida); DMO: Digestibilidade aparente da matéria orgânica ( $\mathrm{g} \mathrm{kg}^{-1}$ de MO ingerida); DPB: Digestibilidade aparente da proteína bruta (g.kg-1 de PB ingerida); DEE: Digestibilidade aparente do extrato etereo (g.kg-1 de EE ingerido); DFDN: Digestibilidade

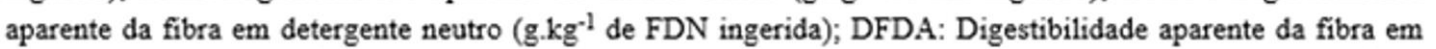
detergente ácido (g.kg-1 de FDA ingerida); DHem: Digestibilidade aparente da Hemicelulose (g. $\mathrm{kg}^{-1}$ de hemicelulose ingerida); DCNF: Digestibilidade aparente dos carboidratos não fibrosos (g. $\mathrm{kg}^{-1}$ de carboidratos não fibrosos ingerido); NDT: Nutrientes digestiveis totais $\left(\mathrm{g} . \mathrm{kg}^{-1} \mathrm{de} \mathrm{MS}\right)=\mathrm{PB}_{\mathrm{dig}}+\left(\mathrm{EE}_{\mathrm{dig}} \times \mathrm{2,25}\right)+\mathrm{FDN}_{\mathrm{dig}}+$ $\mathrm{CNF}_{\text {dig; }}$;20S: Planta colhida a $20 \mathrm{~cm}$ de altura sem adição de inoculante enzimo-bateriano; 20C: Planta colhida a $20 \mathrm{~cm}$ de altura com adição de inoculante; $40 \mathrm{~S}$ : Planta colhida a $40 \mathrm{~cm}$ de altura sem adição de inoculante; 40C: Planta colhida a $40 \mathrm{~cm}$ de altura com adição de inoculante; ${ }^{*}$ Coeficiente de variação, em porcentagem $(\%)$.

\section{Conclusão}

Com a elevação da altura de colheita, ocorreu diferença significativa apenas na redução de lignina. No entanto, essa redução não elevou os coeficientes de digestibilidade dos componentes das silagens.

Pode-se concluir que a microflora epifítica da cultura do milho no presente estudo foi eficaz, proporcionando condições de fermentação suficientes para a adequada conservação da forragem.

\section{Referências}

1. Neylow JM, Kung Jr L. Effects of Cutting Height and Maturity on the Nutritive Value of Corn Silage for Lactating Cows. Journal of Dairy Science. 2003;86(6): 2163-2169. http://dx.doi.org/10.3168/jds.S00220302(03)73806-5.

2. Oliveira FCL, Jobim CC, Silva MS, Calixto Junior M, Bumbieres Junior VH, Roman J. Produtividade e valor nutricional da silagem de híbridos de milho em diferentes alturas de colheita [Productivity and nutritional value of silage of corn hybrids with different heights of harvest]. Revista Brasileira de Zootecnia. 2011; 40(4): 720-727. http://dx.doi.org/10.1590/S1516-35982011000400004 . Portuguese

3. Bernardes TF, Rêgo AC. Study on the practices of silage production and utilization on Brazilian dairy farms. Journal of Dairy Science. 2014; 97(3): 1852-1861. http://dx.doi.org/ 10.3168/jds.2013-7181 . 
4. Silva MSJ, Jobim CC, Poppi EC, Três, TT, Osmari M P. Production technology and quality of corn silage for feeding dairy cattle in Southern Brazil. Revista Brasileira de Zootecnia. 2015; 44(9): 303-313. http://dx.doi.org/10.1590/S1806-92902015000900001

5. Siqueira GR. Aditivos Associados à Ensilagem. In: Reis RA, Bernardes TF, Siqueira GR. Forragicultura: ciência, tecnologia e gestão de recursos forrageiros.1st ed. Jaboticabal-SP: Funep; 2013. p. 689-698. Portuguese

6. Gimenes ALG, Mizubuti IY, Moreira FB, Pereira ES, Ribeiro ELA, Mori RM. Composição química e estabilidade aeróbia em silagens de milho preparadas com inoculantes bacterianos e/ou enzimático [Chemical composition and aerobic stability of corn silages made with bacterials and/or enzymatic inoculants.]. Acta $\begin{array}{lllll}\text { Scientiarum } & \text { Animal } & \text { Sciences. } & 2006 ; & 28(2):\end{array}$ http://periodicos.uem.br/ojs/index.php/ActaSciAnimSci/article/viewFile/640/392. Portuguese

7. Rocha KD, Pereira OG, Valadares Filho SC, Oliveira AP, Pacheco LBB, Chizzotti FHM. Valor nutritivo de silagens de milho (ZeaMays L.) produzidas com inoculantes enzimo-bacterianos [Nutritive value of corn silage (Zea mays L.) produced with enzymatic-bacterial inoculants]. Revista Brasileira de Zootecnia. 2006; 35(2): 389-395. http://dx.doi.org/10.1590/S1516-35982006000200008 . Portuguese

8. Queiroz OCM, Kim SC, Adesogan AT. Effect of treatment with a mixture of bacteria and fibrolytic enzymes on the quality and safety of corn silage infested with different levels of rust. Journal of Dairy Science. 2012; 95(9): 5285-5291. http://dx.doi.org/10.3168/jds.2012-5431

9. Lynch JP, Baah J, Beauchemin KA. Conservation, fiber digestibility, and nutritive value of corn harvested at 2 cutting heights and ensiled with fibrolytic enzymes, either alone or with a ferulic acid esterase-producing inoculant. Journal of Dairy Science. 2015; 98(2): 1-11. http://dx.doi.org/10.3168/jds.2014-8768

10. AOAC - Association of Official Analytical Chemists. Official Methods of Analysis. 15th ed. Vol.1,Agricultural Chemical; Contaminants; Drugs. Arlington: AOAC Inc.; 1990, 768 p. https://law.resource.org/pub/us/cfr/ibr/002/aoac.methods.1.1990.pdf

11. Cherney JH, Cherney DJR. Assessing Silage Quality. In: Buxton DR, Muck RE, Harrison JH. Silage Science and Technology. 1st ed. Madison: ASA-CSSA-SSSA, 2003. p. 31-94. http://dx.doi.org/10.2134/agronmonogr42.c4

12. Van Soest PJ, Robertson JB, Lewis BA. Methods for dietary fiber, neutral detergent fiber, and non starch polysaccharides in relation to animal nutrition. Journal of Dairy Science. 1991; 74(10): 3583-3597. http://www.journalofdairyscience.org/article/S0022-0302(91)78551-2/pdf .

13. NRC - Nutrient Requirements of Dairy Cattle. 7.ed. Washington, DC: National Academy Press, 2001. p. 381.

14. Ferreira EB, Cavalcanti PP, Nogueira DA. Package 'ExpDes.pt'. 2013. [cited 2016 Feb 05] Available from: https://cran.r-project.org/web/packages/ExpDes.pt/ExpDes.pt.pdf .

15. Kung Jr L, Moulder BM, Mulrooney CM, Teller RS, Schmidt RJ. The effect of silage cutting height on the nutritive value of a normal corn silage hybrid compared with Brown Midrib corn silage fed to lactating cows. Journal of Dairy Science. 2008; 91(4): 1451-1457. http://dx.doi.org/10.3168/jds.2007-0236

16. Tres TT, Jobim CC, Pinto RJB, Souza Neto IL, Scapim CA, Silva MSJ. Composição nutricional e digestibilidade "in vitro" de genótipos de milho produzidos em dois anos agrícolas [Nutritional composition and "in vitro" digestibility of corn genotypes evaluated in two years]. Semina: Ciências Agrárias. 2015; 35(6): 3249-3262. http://dx.doi.org/10.5433/1679-0359.2014v35n6p3249 . Portuguese 
17. Caetano H, Oliveira MDS, Freitas Júnior JE, Rêgo AC, Rennó FP, Carvalho MV. Evaluation of corn cultivars harvested at two cutting heights for ensilage. Revista Brasileira de Zootecnia, 2011; 40(1): 12-19. http://dx.doi.org/10.1590/S1516-35982011000100003.

18. Rabelo CHS, Rezende AV, Rabelo FHS, Nogueira DA, Senedese SS, Vieira PF, Bernardes CL, Carvalho A. Silagens de milho inoculadas microbiologicamente em diferentes estádios de maturidade: perdas fermentativas, composição bromatológica e digestibilidade in vitro [Corn silage inoculated with lactic acid bacteria in different maturity stages: fermentative losses, chemical composition and in vitro digestibility]. Ciência Rural. 2014; 44(2): 368-373. http://dx.doi.org/10.1590/S0103-84782014000200028. Portuguese

19. Allen MS, Coors JG, Roth GW. Corn Silage. In: Buxton DR, Muck RE, Harrison JH. Silage Science and Technology. 1 st ed. Madison: ASA-CSSA-SSSA, 2003. p. 547-608. http://dx.doi.org/10.2134/agronmonogr42.c12

20. Restle J, Neumann M, Brondani IL, Pascoal LL, Silva JHS, Pellegrini LG, Souza ANM. Manipulação da altura de corte da planta de milho (Zea mays, L.) para ensilagem visando a produção do novilho superprecoce [Corn (Zea mays, L.) Cutting Height during Silage Processing for Young Beef Cattle Production]. Revista Brasileira de Zootecnia. 2002; 31(3): 1235-1244. http://dx.doi.org/10.1590/S1516-35982002000500021. Portuguese

21. Lewis AL, Cox WJ, Cherney JH. Hybrid, maturity, and cutting height interactions on corn forage yield and quality. Agronomy Journal. 2004; 96(1): 267-274. http://dx.doi.org/10.2134/agronj2004.2670

22. Vasconcelos RC, Von Pinho RG, Rezende AV, Pereira MN, Brito AH. Efeito da altura de corte das plantas na produtividade de matéria seca e em características bromatológicas da forragem de milho [Effect of cutting height of plants on dry matter yield and on bromatologic characteristics of corn forage]. Ciência Agrotecnologia. 2005; 29(6): 1139-1145. http://dx.doi.org/10.1590/S1413-70542005000600006. Portuguese

23. Rezende AV, Watanabe GJ, Rabelo FHS, Rabelo CHS, Nogueira DA. Características agronômicas, bromatológicas e econômicas de alturas de corte para ensilagem da cultura do milho [Agronomic, bromatologic and economical characteristics harvest heights for ensiling of corn]. Semina: Ciências Agrárias, Londrina;36, n. 2, p. 961-970. http://dx.doi.org/10.5433/1679-0359.2015v36n2p961

24. Lauer J. Corn Silage Yield and Quality Trade-Offs When Changing Cutting Height. 1998. [cited 2016 Apr 29]. Available from: http://corn.agronomy.wisc.edu/AA/A020.aspx

25. Kennington LR, Hunt CW, Szasz JI, Grove AV, Kezar W. Effect of cutting height and genetics on composition, intake, and digestibility of corn silage by beef heifers. Journal of Animal Science. 2005; 85(6): 1445-1454. http://dx.doi.org/10.2527/2005.8361445x

26. Assis FB, Basso FC, Lara EC, Raposo E, Bertipaglia LMA, Fernandes LO, Rabelo CHS, Reis RA. Caracterização agronômica e bromatológica de híbridos de milho para ensilagem [Agronomic and chemical characteristics of hybrid corn to ensiling]. Semina: Ciências Agrárias. 2014; 35(6): 2869-2882. http://dx.doi.org/10.5433/1679-0359.2014v35n6p2869. Portuguese

27. Santos RD, Pereira LGR, Neves ALA, Araujo GGL, Aragão ASL, Chizzotti ML. Intake and total apparent digestibility in lambs fed six maize varieties in the Brazilian Semiarid. Revista Brasileira de Zootecnia. 2011; 40(12): 2922-2928. http://dx.doi.org/10.4025/actascianimsci.v32i4.9299. 